\title{
PROBLEM SOLVING IN SCHOOL MATHEMATICS BASED ON HEURISTIC STRATEGIES
}

\section{Jarmila Novotná ${ }^{1}$, Petr Eisenmann², Jiří Přibyl ${ }^{2}$, Jiřina Ondrušováe ${ }^{2}$ Jiří Břehovský ${ }^{2}$}

${ }^{1}$ Charles University in Prague

2Jan Evangelista Purkyně University in Ústí nad Labem

\author{
Highlights \\ - $\quad$ Even short-term work can bear positive results to pupils' approach to problem solving.
}

\begin{abstract}
The paper describes one of the ways of developing pupils' creative approach to problem solving. The described experiment is a part of a longitudinal research focusing on improvement of culture of problem solving by pupils. It deals with solving of problems using the following heuristic strategies: Analogy, Guess - check - revise, Systematic experimentation, Problem reformulation, Solution drawing, Way back and Use of graphs of functions. Most attention is paid to the question whether short-term work, in this case only over the period of three months, can result in improvement of pupils' abilities to solve problems whose solving algorithms are easily accessible. It also answers the question which strategies pupils will prefer and with what results. The experiment shows that even short-term work can bear positive results as far as pupils' approach to problem solving is concerned.
\end{abstract}

\section{Keywords}

Problem Solving, Solving Strategies, Strategy of Analogy, Graphical Representation, Systematic Experimentation, Strategy of Reformulation, Way Back
Article type

Full research paper

Article history

Received: November 6, 2013

Received in revised form: February 12, 2014

Accepted: February 21, 2014

Available on-line: March 31, 2014

Novotná, J. et al. (2014) "Problem Solving in School Mathematics Based on Heuristic Strategies", Journal on Efficiency and Responsibility in Education and Science, Vol. 7, No. 1, pp. 1-6, online ISSN 1803-1617, printed ISSN 2336-2375, doi: 10.7160/eriesj.2013.070101.

\section{Introduction}

It is a truth universally acknowledged that problem solving forms the basis for successful mathematics education; solving of carefully selected problems helps to develop, refine and cultivate creativity (Kopka, 2010, Foreword). How can one tell whether a pupil has learned anything from mathematics? It is generally acknowledged that problem solving is an indicator of the state of grasping concepts and ideas pupils are learning. Problem solving skills develop fast if the solver gets new and new experience with the activity. Pupils' performance in problem solving improves if they repeatedly meet the same type of problem or if they can make use of their previous experience (Eysenck, 1993).

A teacher's attitude and the teaching strategies he/she uses significantly influence educational outcomes, see e.g. (Švec, 2012). Observations from Czech schools suggest that pupils as well as teachers prefer problems in whose case the algorithm suitable for their solution is apparent, in whose case there are no doubts about the choice of the suitable algorithm (Novotná, 2000). In that case the class does not have to undergo the painstaking procedure of looking for this algorithm and can omit the often lengthy and difficult journey to grasping of the problem. The role of the teacher is simpler, he/she only has to detect the place where pupils make mistakes and assess correctness of their solutions. That is the reason why teachers often choose problems in whose case the search for the appropriate algorithm is easy and also often hint at the suitable solving procedure. This means pupils instead of solving a problem simply apply some algorithm chosen according to the signals from the assignment or the teacher. Then they fail if they are to solve non-standard problems whose assignment does not contain elements they are used to, elements that serve as indicators for selection of the right solving strategy. They feel helpless if they face an atypical, unusual problem or a problem set in an unknown context. Needless to say that this often happens in case of application problems, where pupils are expected to use mathematics for solution to problems from everyday life.

One of the indicators telling a teacher whether a pupil understands the subject matter is the pupil's ability to come up with new, original solving procedures when solving a new problem.

But this is something a teacher cannot teach directly. He/she can expect this approach from their pupils, he/she can ask for it, support them in it but he/she cannot teach it (Sarrazy and Novotná, 2013). This is one of the key concepts of didactics of mathematics, the didactical contract and paradoxes connected to it (Brousseau, 1997).

Looking for ways of improvement of understanding in mathematics has been in the centre of attention of a number of researches and comparative studies worldwide Examples of these are for example two large scale studies - TIMSS a PISA. Between 1995 and 2007 Czech pupils' achievement in mathematics was declining; since 2007 a statistically significant improvement has shown on the level of $4^{\text {th }}$ graders. The decreasing achievement of Czech pupils occurred also in PISA between 2003 and 2009. That is why it is important to look for ways of improving the situation (Mullis et al., 2012; OECD, 2010).

Changes in approaches to problem solving in school practice depend on changes in teachers' attitude and approaches to mathematics education, see e.g. (Tichá and Hošpesová, 2006). 
Obviously the necessary condition for teaching mathematics via problem solving without transmission of ready-made knowledge, i.e. condition for creative solving, is teachers' solid knowledge of mathematics, their own experience with creative approach to problem solving, but also sufficient information and materials ready for use in the classroom. Important is the so called specialized content knowledge (Ball, Thames and Phelps, 2008); this knowledge includes identification of key mathematical concepts and possibilities in the given activity, recognition of different forms of representation of mathematical concepts and operations and other strengths and weaknesses. The paper has been developed as extension of the paper (Novotná et al., 2013).

\section{Our research}

the sense of production of original solutions to unusual situations) are shown. Attention is paid especially to the possibilities a teacher has to change their pupils' approach to problem solving from using algorithms they had been told to creative search for suitable, albeit "unschool-like" strategies. This research is part of a longitudinal research focusing on improvement of culture of problem solving by pupils (Břehovský et al., 2013).

The key questions of mathematics education are: Should the teacher direct his/her teaching towards good mastery of algorithms or towards development of students' creativity? Should all students or only the highly able ones be given the opportunity to work creatively? (Sarrazy and Novotná, 2013)

\section{Theoretical framework}

One of the approaches to the teaching/learning process perceives this process as a sequence of situations (natural or didactical) whose result is modification of a student's behaviour typical for getting new knowledge (Brousseau, 1997).

The concept of "problem solving" is a very loosely defined notion, a kind of umbrella term for a number of different theoretical approaches (Nesher, Hershkowitz and Novotná, 2003). If we admit that solving a genuine problem is not just a matter of following a particular algorithm, we have to define heuristic strategies used for their solution. First Polya (1945) and then Schoenfeld (1985) suggested several general strategies for solving word problems based on questions like: What is the unknown? What are the data? What are the conditions? Do you know a related problem that has already been solved? Prepare a plan for the solution. Verify the gained results.

Fan and Zhu (2007) list among heuristic strategies also the following strategies: "Draw a diagram", "Guess and check", "Look for a pattern", "Make a systematic list", "Use beforeafter conception". Eisner (1982), Sanford (1985), Kaufmann (1985) state that it is visual imagination which is crucially important in problem solving. Stacey (1991) characterizes the "Trial and error strategy" as an intuitive strategy that anybody can use.

\section{Studied heuristic strategies}

The developed heuristic strategies are the author's modification of strategies published in (Kopka, 2013) and (Polya, 2004).

Strategy of analogy: Analogy is a type of similitude. If we are to solve a particular problem we find an analogical problem, i.e. a problem that will deal with a similar problem in a similar way. If we manage to solve this similar problem, we can then apply the method of its solution or its result in the solution to the original problem.
Guess - check - revise: This is a strategy in which we first, drawing from our experience, make a guess about the solution to the given problem. Then we check whether the solution meets the conditions of the assignment. The next guess is made with respect to the previous result. We carry on in this way until we find a solution.

Systematic experimentation: Systematic experimentation is a strategy in which we try to find the solution to a problem using several experiments. First we apply some algorithm that we hope will help us solve the problem. Then we proceed in a systematic way and change the input values of the algorithm until we find the correct solution.

Problem reformulation: When using this strategy we reformulate the given problem and make another one which may either be brand new, is easier for us to solve and whose solution is either directly the solution to the original problem or facilitates its solution. A specific and very important example of this strategy is translation of a word problem from one language of mathematics to another. Classical geometrical problems such as trisection of an angle were easy to solve when translated to the language of algebra.

Solution drawing: When using graphical representation we usually visualize the problem by making a drawing. We write down what is given and often also what we want to get. The drawing we get in this way is called an illustrative drawing as it illustrates the solved problem. Sometimes we can see the solution of the problem immediately in this drawing. However, in most cases we must manipulate with the drawing (e.g. we add suitable auxiliary elements) and we solve the problem with the help of this modified drawing. We call this drawing the solution drawing

Working backwards: This is a very common strategy in mathematics. We assume that what we have to find/prove/ construct holds/exists. Then we try to deduce from this assumption something we already know or something that is easy to prove/calculate/construct. Thus we in fact try to get from the end to the starting situation as close as possible. The procedure is reverted in the final calculation/proof/construction.

Use of graphs of functions: When there are functions in the problem assignment or when it turns out within the solving process that it is desirable to introduce functions then it is usually good to draw graphs of these functions. These graphs often considerably contribute to finding the solution to the given problem.

\section{Material and methods}

The paper describes assessment of the first stage of a short-term experiment from our research. The experiment was carried out in two lower secondary schools in Ústí nad Labem $\left(7^{\text {th }}\right.$ grade 26 , resp. 28 pupils aged 13) and two upper secondary grammar schools (Most and Lovosice - third grade-19, resp. 11 students aged 18).

The experiment lasted three months. In this period the teachers presented to their pupils and students prepared problems (in total about 30) that could be efficiently solved using the above described heuristic strategies. They were those general strategies that do not seem natural to the pupils, that they rarely or never come across at school but are very useful.

In case of lower secondary schools these strategies are the strategies of Analogy, Working backwards, Guess - check - revise and Systematic experimentation. In case of upper secondary grammar schools these strategies were Problem 
reformulation, Solution drawing, and Use of graphs of functions. The aim of this work was to make pupils and students use these strategies correctly.

The teachers were given a sufficient number of problems that can be solved using one of the above described strategies. Most often they were such problems in whose case the use one of the strategies results in faster, more efficient or elegant solution to the given problem. Most of the used problems were developed by authors of this paper or are their modifications of problems published in Czech collections of mathematical problems. In case that the problem is borrowed from a publication, the publication is cited.

Teachers kept an updated record of spontaneous use of any of the discussed strategies by their pupils and their reaction to the expected solution reached with the help of this heuristic strategy. Problem solving always had constructivist form. There was always some pupil or student who demonstrated and explained their solving procedure to other pupils. The teachers encouraged their pupils to search for more solving procedures. This approach to solving was used both in case of problems from the lessons targeted at the current subject matter and short problems used as warm-up activities in the beginnings of some lessons.

The pupils sat an initial and a final test in the beginning and end of the experiment. These tests consisted of 4 to 5 problems.

\section{Conditions of the test:}

The pupils were given the time limit of 40 minutes. They were allowed to use simple calculators and computers on their desks. All the pupils had basic skills in use of spreadsheet Excel. There was no significant intervention of the teachers in the solving process.

In the following section we show the solved problems. In case of each of the problems we also name the heuristic strategy that leads to efficient solution. We present a short illustrative use of the stated strategy.

Lower secondary school:

1. A car covered the distance of $420 \mathrm{~km}$ and used up 291 of petrol. What was its average petrol consumption per $100 \mathrm{~km}$ ?

Efficient solving strategy: Analogy

We formulate a problem that is easier numerically and evoke the process of finding the solving procedure: A car covered the distance of $200 \mathrm{~km}$ and used up $16 \mathrm{l}$ of petrol. What wasits average petrol consumption per $100 \mathrm{~km}$ ?

The answer lends itself automatically - the average car consumption per $100 \mathrm{~km}$ was 8 litres.

How did we arrive at this result? The calculation can be reconstructed as follows: $16 /(200 / 100)=8$.

Let us now return to the original problem and let us solve it in the same way. The answer is: The average consumption of the car per $100 \mathrm{~km}$ is about 6.9 litres.

2. (Cihláŕ and Zelenka, 1998). State the two consecutive odd numbers whose product is 323 . Efficient strategy: Guess check - revise

In Table 1, one odd number is chosen arbitrarily and the consecutive odd number and the product of both are calculated. The last column indicates if the numbers solve the assigned problem or if we have to start again with a greater or smaller odd number. The process is repeated until the solution is discovered.

\begin{tabular}{|c|c|c|c|}
\hline 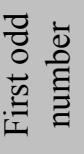 & 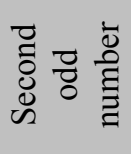 & $\begin{array}{l}\overleftarrow{0} \\
\stackrel{0}{0} \\
0 \\
0 \\
0\end{array}$ & $\begin{array}{l}\stackrel{\tilde{\omega}}{\text { }} \\
\stackrel{\oplus}{=} \\
\tilde{n}\end{array}$ \\
\hline 1 & 3 & 3 & No. The product is (too)small. \\
\hline 11 & 13 & 143 & No. The product is small. \\
\hline 21 & 23 & 483 & No. The product is small. \\
\hline 19 & 21 & 399 & No. The product is small. \\
\hline 17 & 19 & 323 & Yes. It is the solution. \\
\hline
\end{tabular}

Table 1: Example of Guess - check - revise

The answer is: The sought numbers are 17 and 19 .

3. The number is ten less than twice the number. What number is it?

Efficient solving strategy: Systematic experimentation

The experimentation was conducted using a spread sheet.

\begin{tabular}{|c|c|c|c|}
\hline $\mathrm{n}$ & $\mathrm{n}+10$ & $2 \mathrm{n}$ & Does $\mathrm{n}+10=2 \mathrm{n}$ hold? \\
\hline 1 & 11 & 2 & No \\
\hline 2 & 12 & 4 & No \\
\hline 3 & 13 & 6 & No \\
\hline 4 & 14 & 8 & No \\
\hline 5 & 15 & 10 & No \\
\hline 6 & 16 & 12 & No \\
\hline 7 & 17 & 14 & No \\
\hline 8 & 18 & 16 & No \\
\hline 9 & 19 & 18 & No \\
\hline 10 & 20 & 20 & Yes \\
\hline
\end{tabular}

Table 2: Example of Systematic experimentation

The answer is: The desired number is 10 .

4. When driving on the motorway, an interesting symmetrical number showed on my odometer: 24942. After two more hours of driving there was another interesting symmetrical number on the odometer. What number was it? Did I observe the speed limit?

Efficient solving strategy: Systematic experimentation

In systematic experimentation, one can use spread sheet and in a finite number of steps, the solution will be discovered quite fast (use of ICT is not essential but it facilitates calculations). If we take into account conditions of the context we realize that the number on the odometer is 24942. Having driven on the motorways for only two hours, the figure in the position of tens of thousands cannot change. Then it is obvious, that also the figure in the position of units cannot change. Therefore the number of steps needed to find the solution decreases. In Table 3 , the digit in the place of hundreds regularly increases by 1 and the other two digits are changed correspondingly is such a way that the number remains symmetrical.

\begin{tabular}{|c|c|c|c|}
\hline Step & On the odometer & $\begin{array}{c}\text { Covered } \\
\text { distance }\end{array}$ & $\begin{array}{c}\text { Average } \\
\text { speed }\end{array}$ \\
\hline 0 & 24942 & 0 & 0 \\
\hline 1 & 25052 & 110 & 55 \\
\hline 2 & 25152 & 210 & 105 \\
\hline 3 & 25252 & 310 & 155 \\
\hline 4 & 25352 & 410 & 205 \\
\hline
\end{tabular}

Table 3: Example of Systematic experimentation 
Table 3 shows the first number that can be observed on the odometer is 25052 . In this case, the driver was observing the speed limits. The next symmetrical number that can be observed on the odometer is 25152 . And also in this case the driver was observing the speed limits. If speed limits are observed, the following symmetric number cannot be come across on the odometer.

The answer is: The maximum speed on the motorway in the Czech Republic is $130 \mathrm{~km} / \mathrm{h}$. It is obvious that if we observe the speed limits, only 25052 or 25152 can be come across on the odometer. If the driver drives faster than is allowed, in addition numbers 25252 and 25352 can be come across on the odometer. 5. Adam says: "I first lost one half of my glass marbles and then one half of what was left. Now I have 19 glass marbles." How many glass marbles did Adam have in the very beginning?

Efficient solving strategy: Working backwards

At the end, Adam had 19 marbles. Before the second loss, he had twice as many, i.e. 38 marbles. Analogically before the first loss, he had 76 marbles.

The answer is: At the very beginning, Adam had 76 marbles.

Note: In case of using an equation (which is fully legitimate in this case) the solver faces the necessity to express the "half of the half from the previous step" $(1 / 2)[x-(1 / 2) x]$. This might be a difficulty that the solver can prevent if they use the Working backwards strategy.

Upper secondary grammar school:

1. Determine the number of all roots of the equation $x^{2}=2^{x}$.

Efficient solving strategy: Using graphs of functions.

In Fig. 1 there are graphs of both functions $x^{2}$ and $2^{x}$. The roots of the equations are represented by the intersection points of the graphs.

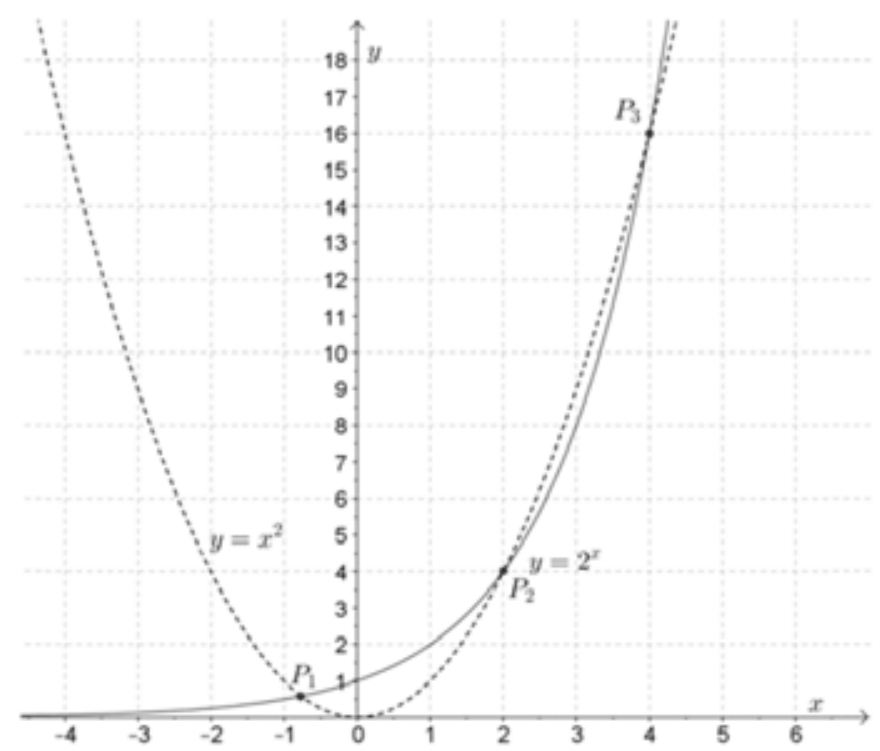

Figure 1: Graphical representation of the roots of the equation

2. (Zeitz, 2007). let there be a square inscribed in a circle and the circle be inscribed in a square. Determine what part of the larger square is formed by the smaller square (see Fig. 2).

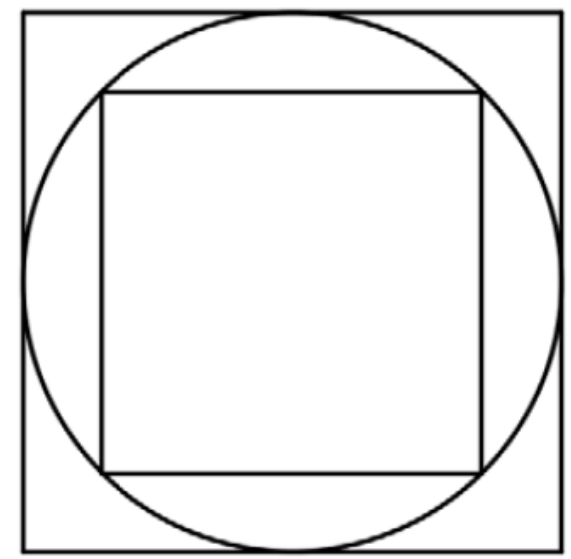

Figure 2: Figures assigned in Problem 2

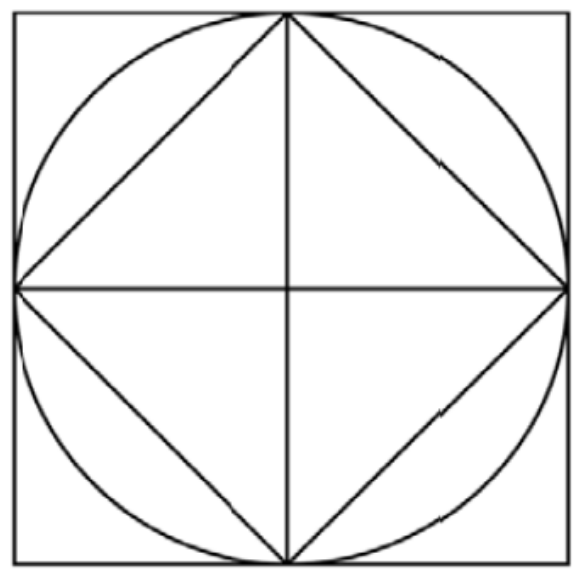

Figure 3: Solution drawing

Efficient solving strategy: Solution drawing (see Fig. 3).

3. Decide which of the fraction is greater: $125 / 126$ or $124 / 125$.

Efficient solving strategy: Problem reformulation

The assignment of the reformulated problem: Let us have two equal pizzas (congruent circles). Let us cut the first one to 125 equal parts and the other to 126 equal parts. We eat one piece of each of the pizzas. In which pizza is there more left?

4. (Maláč and Kurfürst, 1981). Calculate the area of the "drop" whose circumference is composed from circle arcs. Data in Fig. 4 are given in centimetres.

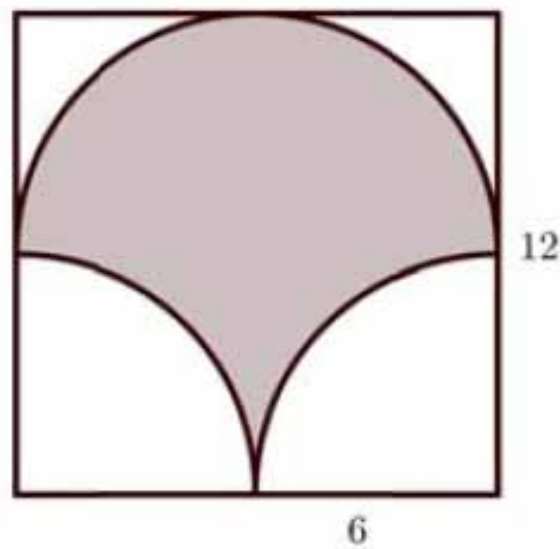

Figure 4: Figure assigned in problem 4

Efficient solving strategy: Solution drawing

Fig. 5 justifies that the area of the "drop" equals the area of the rectangle with the lengths of sides $6 \mathrm{~cm}$ and $12 \mathrm{~cm}$. 


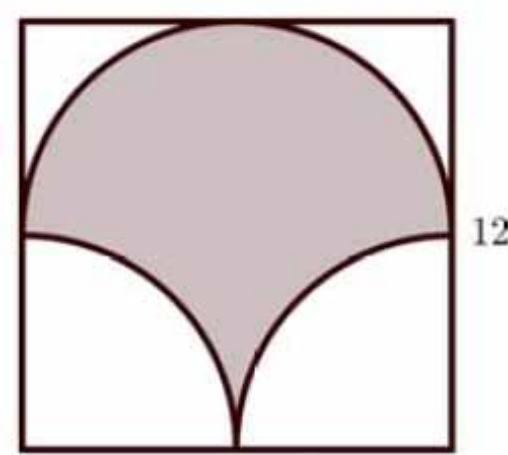

6

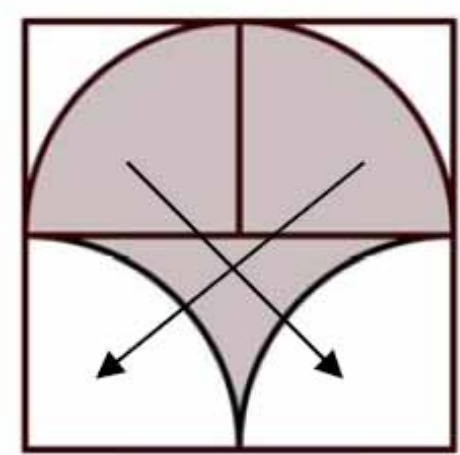

Figure 5: Movement of figures
The answer is: The area of the drop is $72 \mathrm{~cm}^{2}$.

\section{Results}

\section{Research questions}

1. Is it possible to achieve any progress in the ability to solve mathematical problems using the above described heuristic strategies for such a short period of time (3 months)?

2. In case of which strategies is this possible and which cannot be "implanted" in such a short period of time?

3. Does the above described work of the teachers with the pupils and students have any side effects?

4. If so, are they positive or negative?

Lower secondary school:

Strategies trained: Analogy, Working backwards, Guess - check - revise and Systematic experimentation.

1. There was no significant progress in the use of the strategy of Analogy. This showsthat the three month period was too short.

2. There was a considerable progress in the use of both strategies based on experimentation, i.e. Guess - check revise and Systematic experimentation. Having compared the initial and the final tests it can be stated that the growth in use of this strategy was $30 \%$ percent. Moreover, almost all problems solved using these solving strategies in the final test were solved correctly. And the situation was similar in case of the strategy Working backwards was more frequent in the final tests. This shows that also this strategy is a heuristic strategy that can be learned by repetition (after a short use).

Upper secondary school:

Strategies trained: Problem reformulation, Solution drawing and Use of graphs of functions.

1. There was no significant progress in the used strategies of Problem reformulation and Solution drawing. This shows that the three month period was too short.

2. There was significant progress in the use of the strategy Using graphs of functions. Having compared the initial and the final tests it can be stated that the growth in use of this strategy was $50 \%$ percent. Moreover, almost all problems solved using this solving strategy in the final test were solved correctly.

\section{Discussion}

Results of the short-term experiment discussed in this paper are promising. This is confirmed not only by the observed changes in the use of solving strategies by the pupils but also by spontaneous comments of the teachers involved in the experiment. In general, the teachers stated the following:

- Some pupils and students (about one half of them) stopped being afraid to solve word problems at the end of the experiment, they stopped withdrawing from the solution in case they were not sure of how to solve them from the very beginning.

- They learned to look for the solution, not to give up.

- Also pupils and students who used to be passive in lessons of mathematics started to get involved in problem solving.

- Pupils and students started to comment on their solving procedure, justify it and in case of written solutions produce a verbal answer.

In case of upper secondary schools (where one of the developed strategies was the strategy Use of graphs of functions) both teachers involved in the experiment also stated the following:

- Students began to use graphs of functions for problem solving even in situation when this would not have occurred to them before. In other words they started to use graphs of functions spontaneously as one of the possible solving procedures.

In the experiment presented in this article heuristic strategies of Fan and Zhu (2007) were enriched by two others: the strategy of analogy and problem reformulation. Moreover, the experiment confirmed the importance of visual imagination for problem solving stated by Eisner (1982), Sanford (1985) or Kaufmann (1985).

Not all of the strategies used in the presented experiment can be considered as intuitive strategies that everybody can use (Stacey, 1991); this is valid for two of them: Guess - check - revise and Systematic experimentation.

\section{Conclusions}

Apart from the short-term experiment whose implementation and results are discussed in this paper, we also work on a longitudinal experiment (systematic work for the period of 14 months). We expect the pupils to be able to use actively in the end of this experiment problem solving strategies that they choose as optimal for the specific problem. In this sense we say that their "Culture of problem solving" will improve (for details see e.g. Eisenmann, Novotná and Přibyl, 2013). 
The research also focuses on the question which of the explored strategies is most often spontaneously selected by the pupils (i.e. which they find most natural) and which they select rarely or never (i.e. which they find unnatural). And most importantly what this depends on.

\section{Acknowledgement}

The research was supported by the project GAČR P407/12/1939.

\section{References}

Ball, D., Thames, M.H. and Phelps, G. (2008) 'Content knowledge for teaching. What makes it special?', Journal of Teacher education, vol. 59, no. 5, pp. 389-407.

Brousseau, G. (1997) Theory of didactical situations in mathematics, Dordrecht: Kluwer Academic Publishers.

Břehovský, J., Eisenmann, P., Ondrušová, J., Přibyl, J. and Novotná, J. (2013) 'Heuristic Strategies in Problem Solving of 11-12-year-old pupils', Proceedings of SEMT '13, Prague, pp. $75-82$.

Cihlár̆, J. and Zelenka, M. (1998) Matematika 8. Praha: Pythagoras Publishing, a.s.

Eisenmann, P., Novotná, J. and Přibyl, J. (2013) 'A Tool for Evaluation of Culture of Pupil Solving of Mathematical Problems', Proceedings of the $37^{\text {th }}$ Conference of the International Group for the Psychology of Mathematics Education, Kiel, vol. 5, p. 223.

Eisner, E.W. (1982) Cognition and Curriculum: A Basis for Deciding What to Teach, New York: Addison-Wesley Longman Limited.

Eysenck, M.W. (1993) Principles of Cognitive Psychology, Hove: Lawrence Erlbaum Associates Ltd.

Fan, L. and Zhu,Y. (2007) 'Representation of Problem-Solving Procedures: A Comparative Look at China, Singapore, and US mathematics textbooks', Educational Studies in Mathematics, vol. 66 , no. 1 , pp. 61-75.

Kaufmann, G. (1985) 'A theory of symbolic representation in problem solving', Journal of Mental Imagery, vol. 9, no. 2, pp. 51-70.

Kopka, J. (2010) Ako riešit' matematické problémy, Ružomberok: Katolická univerzita v Ružomberku.

Kopka, J. (2013) Uměni řešit matematické problémy. Praha: HAV - Hoza.

Maláč, J. and Kurfürst, J. (1981) Zajímavé úlohy z učiva matematiky ZŠ, Praha: SPN.

Mullis, I.V.S., Martin, M. O., Foy, P. and Arora, A. (2012) TIMSS 2011 international results in mathematics. Chestnut Hill: TIMSS and PIRLS International Study Center, Boston College.

Nesher, P., Hershkovitz, S. and Novotná, J. (2003) 'Situation Model, Text Base and What Else? Factors Affecting Problem Solving', Educational Studies in Mathematics, vol. 52, no. 2, pp. 151-176.

Novotná, J. (2000) Analýza řešení slovních úloh, Praha: Univerzita Karlova, Pedagogická fakulta.

Novotná, J., Eisenmann, P., Přibyl, J., Ondrušová, J. and Břehovský, J. (2013) 'Heuristic strategies in problem solving in school mathematics', Proceedings of the 10th International Conference on Efficiency and Responsibility in Education, Prague, pp. 461-468.

OECD (2010) PISA 2009 Results: What Students Know and
Can Do - Student Performance in Reading, Mathematics and Science (Volume I). Available from http://www.oecd.org/pisa/ pisaproducts/48852548.pdf.

Polya, G. (1945) How to Solve It, Princeton: Princeton University Press.

Polya, G. (2004) How to solve it: a new aspect of mathematical method, Princeton: Princeton University Press.

Sanford, A.J. (1985) Cognition and Cognitive Psychology, Hillsdale, Weidenfeld \& Nicolson Ltd.

Sarrazy, B. and Novotná, J. (2013) 'Mathematical creativity and highly able students: What can teachers do? An analysis of didactical regulations of different cognitive capacities in teaching and learning relational calculations to 9-10-year-old students', Proceedings CERME 8. Available from http://www. cerme8.metu.edu.tr/wgpapers/WG7/WG7_Novotna.pdf.

Schoenfeld, A. (1985) Mathematical Problem Solving, London: Academic Press.

Stacey, K. (1991) 'The effects on student's problem solving behavior of long-term teaching through a problem solving approach', Proceedings of the $15^{\text {th }}$ conference of the international group for the psychology of mathematics education, vol. 3, pp. 278-285, Assisi.

Švec, V. (2012) 'Experience: To teach or to reach?', Proceedings of the $9^{\text {th }}$ International Conference on Efficiency and Responsibility in Education, Prague, pp. 552-562.

Tichá, M. and Hošpesová, A. (2006) 'Qualified Pedagogical Reflection as a Way to Improve Mathematics Education', Journal for Mathematics Teachers Education. Special Issue: Inter-Relating Theory and Practice in Mathematics Teacher Education, vol. 9, no. 2, pp. 129-156.

Zeitz, P. (2007) The Art and Craft of Problem Solving, John Wiley \& Sons, Inc. 